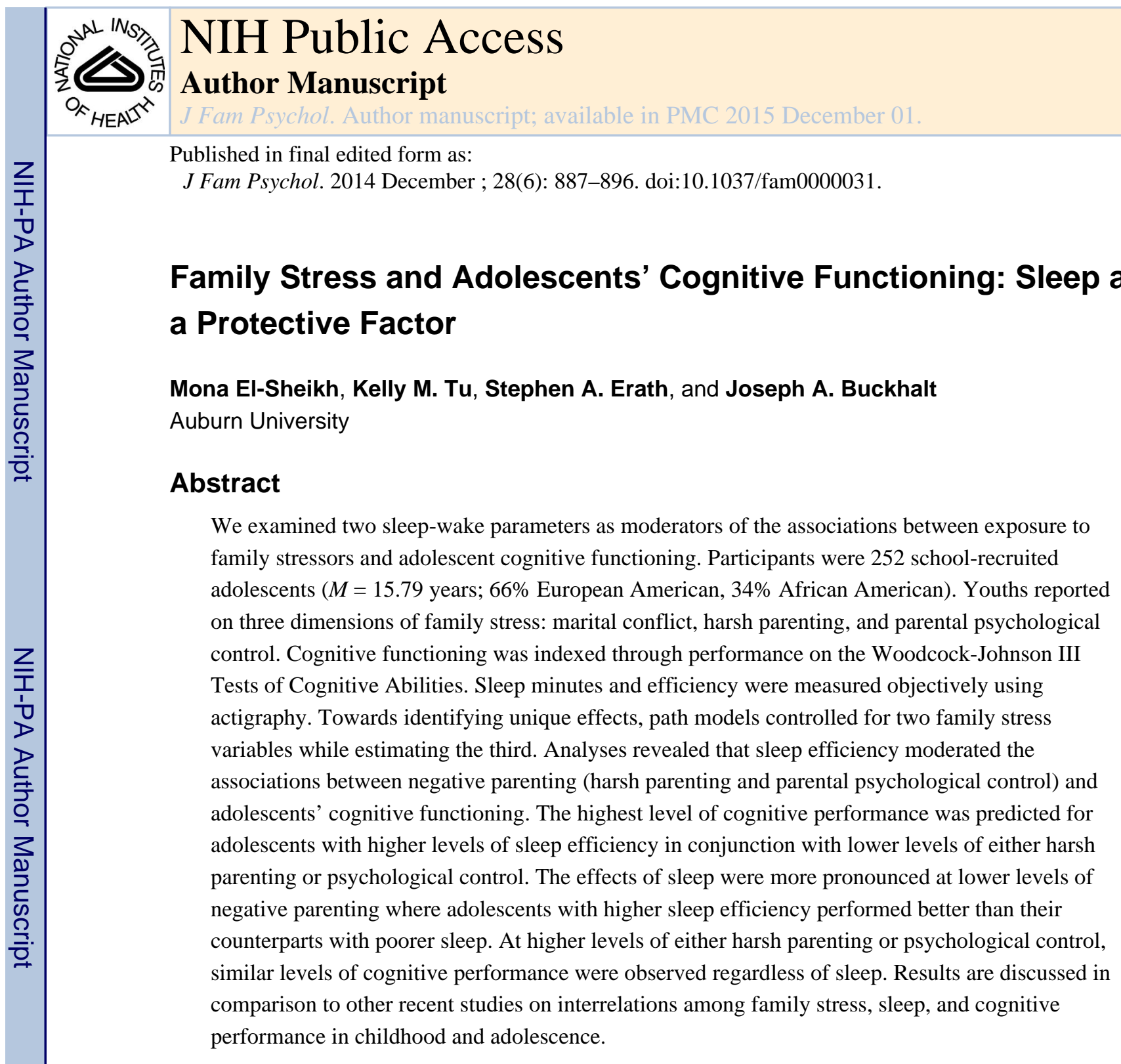

\title{
Keywords
}

family stress; adolescent sleep; cognitive functioning; actigraphy

Environmental and bioregulatory factors contribute to adolescents' cognitive functioning, and exposure to family stressors and adolescents' sleep may independently and/or interactively promote or hinder youths' intellectual functioning. Family stressors, including marital conflict (Koenen, Moffitt, Caspi, Taylor \& Purcell, 2003), harsh parenting (Shumow, Vandell, \& Posner, 1998), and parental psychological control (Byford, Kuh, \& Richards, 2012) are associated with poorer cognitive performance in children. Yet, not all youths who are exposed to such family risk exhibit poor cognitive functioning, and questions remain about why some adolescents may be more or less at risk.

Correspondence: Mona El-Sheikh, Ph.D., Human Development and Family Studies, Auburn University, AL 36849. elshemm@auburn.edu. 
Bioregulatory factors including sleep could influence the extent to which family parameters affect developmental outcomes in children and adolescents. Reduced sleep duration and poor sleep quality may exacerbate the effects of marital conflict (Lemola, Schwarz, \& Shiffert, 2012), parental psychological control (El-Sheikh, Hinnant, Kelly, \& Erath, 2010) and parent-child insecure attachment (Keller, El-Sheikh, \& Buckhalt, 2008) on children's internalizing and externalizing symptoms (El-Sheikh et al., 2010; Lemola et al., 2012) and academic performance (Keller et al., 2008). However, sleep has not been investigated as a moderator of risk in the context of harsh parenting or as a moderator of associations between familial stressors and adolescents' intellectual functioning. Building on this emerging literature, we examined whether sleep may attenuate or exacerbate the effects of multiple family stressors on adolescents' cognitive functioning/intellectual ability; these terms are used interchangeably.

\section{Family Stress}

Three dimensions of family stress were examined including marital conflict, harsh parenting, and parental psychological control. Marital conflict refers to acts and/or threats of physical violence and verbal/psychological aggression between partners (Straus, Hamby, Boney-McCoy, \& Sugarman, 1996). Harsh parenting indicates similar acts of aggression that parents direct towards children (Straus, Hamby, Finkelhor, Moore, \& Runyan, 1998). Parental psychological control refers to parents' attempts to control a child's behaviors, thoughts, and feelings in an intrusive manner that disregards the child's autonomy (Barber, 2002). Although these indices of family stress are related (e.g., Erel \& Burman, 1995), they are distinct constructs that provide insight into different facets of family functioning (Buehler \& Gerard, 2013). Examining these aspects of family functioning may be particularly relevant during adolescence given changes to family dynamics as youths seek to gain autonomy despite parents' desires to retain some control over adolescents' lives (Longmore, Manning, \& Giordano, 2013). Further, consistent with recent calls in the sleepfamily functioning literature (El-Sheikh, 2011), examining the unique contributions of multiple facets of family stress is likely to provide a more nuanced understanding of how different family processes may uniquely influence adolescents' cognitive functioning in the context of their sleep.

Associations between family stressors and youths' adjustment are well-established. High levels of internalizing and externalizing problems are found among children exposed to marital conflict (Cummings \& Davies, 2011), harsh parenting (Klahr, McGue, Iacono, \& Burt, 2011), and psychological control (Soenens et al., 2008). Additionally, there is evidence linking marital conflict (Buehler \& Gerard, 2013), harsh parenting (Dotterer, Hoffman, Crouter, \& McHale, 2008), and parental psychological control (Bean, Bush, McKenry, \& Wilson, 2003) with lower levels of academic performance and achievement assessed by school grades. In the present investigation, cognitive functioning was assessed through performance on a well-established and standardized test battery of multiple facets of intellectual ability (Woodcock-Johnson III (WJ-III); Woodcock, McGrew, \& Mather, 2001). Although academic performance and achievement are related to intellectual ability/ intelligence, they are distinct constructs (Kaufman, Reynolds, Liu, Kaufman, \& McGrew, 2012). Whereas achievement refers to acquired knowledge and is often assessed through 
grades and performance in specific subject areas, intellectual ability or cognitive functioning as defined in this study refers more broadly to an individual's ability to learn, reason or think abstractly, and process information.

Exposure to family stress may be specifically linked with poorer intellectual ability because family conflict and disrupted parenting practices are frequently threatening to youth, activating their stress response systems. Continued activation of the hypothalamic pituitary adrenal stress response system yields chronic and elevated cortisol levels, which can result in neuronal death, and thus undermine brain development (McEwen, 2009) and cognitive functioning (Koenen et al., 2003; Romeo, 2013). Similarly, family risk may disrupt autonomic nervous system activity, which in turn could compromise cognitive functioning (Hinnant, El-Sheikh, Keiley, \& Buckhalt, 2013). The effects of environmental stressors on brain functioning may be particularly profound during childhood and adolescence as the brain matures rapidly (Dahl \& Spear, 2004) and as stress responses (e.g., cortisol) increase in adolescence (Romeo, 2013).

The small literature that has examined the link between family stress and youths' intellectual ability has yielded evidence of modest associations. Compared to young children from lower conflict homes, children exposed to greater levels of marital conflict exhibited lower intelligence test scores (Koenen et al., 2003; Ybarra, Wilkens, \& Lieberman, 2007). In these studies, intelligence was assessed with well-validated and standardized cognitive tests for young children. Further, in comparison to negative parent-child interactions (e.g., hostility), positive parent-child interactions (e.g., warmth, responsiveness) were correlated with higher standardized intelligence test scores in young children (Estrada et al., 1987). Similarly, mothers' coercive parenting, or the use of threats to achieve desired behavior, was negatively associated with children's reading, sentence completion, and vocabulary (Byford et al., 2012). Findings from these studies suggest that multiple dimensions of family processes are linked with cognitive functioning and intellectual ability.

\section{Adolescent Sleep}

Insufficient and poor quality sleep are common among typically developing youth (Mindell \& Owens, 2010), particularly during adolescence because maturational changes in circadian rhythms affect adolescents' sleep-wake cycles (Brand \& Kirov, 2011). For example, adolescents experience reduced sleep duration because they go to bed later than younger children, yet their wake-times are determined by school start times during the school year (Crowley, Tarokh, Carskadon, 2014). A large literature has demonstrated that insufficient and lower quality sleep are associated with poor cognitive functioning (effect sizes $r \mathrm{~s}=$. $07-.10, p s<.01$, as reported in a meta-analysis by Astill et al., 2012). Further, there is evidence that inadequate sleep might disrupt brain development through neuronal loss and alterations in brain activity, which in turn could compromise adolescents' cognitive functioning (Jan et al., 2010; Vriend et al., 2013).

In addition to direct effects, sleep could function as a moderator of the associations between exposure to family stress and adolescents' cognitive functioning. Sleep is associated with emotional functioning, which in turn may influence the level of stress adolescents 
experience in the context of family risk. Shorter sleep duration is linked with increased negative emotions (Leotta, Carskadon, Acebo, Seifer, \& Quinn, 1997) and decreased ability to regulate emotions (Gruber, Cassoff, Frenette, Wiebe, \& Carrier, 2012). Indeed, under a sleep restriction condition ( 6.5 hours in bed), compared to a longer sleep condition (10 hours in bed), adolescents exhibited poorer emotion regulation (Baum et al., 2014). Consistent with a cumulative risk perspective (Sameroff, Bartko, Baldwin, Baldwin, \& Seifer, 1998), inadequate sleep may function as a vulnerability factor and exacerbate the negative effects of family stress on cognitive functioning.

Conversely, longer and better quality sleep may function as a protective factor as sleep is necessary to sustain attention that is needed for learning and cognitive performance (Beebee, 2011). Findings from experimental studies reveal that sleep extension, compared to sleep restriction, is associated with improved short-term and working memory and overall cognitive performance among children and adolescents (Dewald-Kauffman, Oort, \& Meijer, 2013; Sadeh, Gruber, \& Raviv, 2003; Vriend et al., 2013).

A growing body of literature supports the moderating role of sleep in the link between family functioning and youths' adaptation. Consistent with a cumulative risk perspective (Sameroff et al., 1998), marital conflict predicted higher levels of aggression only among adolescents who reported shorter weekday sleep duration and less consistent sleep schedules (Lemola et al., 2012). Further, for a subsample of participants from higher socioeconomic backgrounds, better sleep quality (actigraphy-based sleep efficiency) functioned as a protective factor against depression and anxiety in the context of maternal psychological control (El-Sheikh et al., 2010). Additionally, in the context of family economic adversity, better sleep quality protected children against poorer cognitive performance (Buckhalt, ElSheikh, Keller, \& Kelly, 2009).

A different pattern of moderation effects was observed in two longitudinal studies. Maternal sensitivity during infancy predicted lower internalizing and externalizing behaviors (Bordeleau, Bernier, \& Carrier, 2012) and greater attachment security (Bernier, Belanger, Tarabulsy, Simard, \& Carrier, in press), but only among children with longer sleep duration in infancy. Maternal sensitivity also predicted higher executive functioning and perspective taking among children with more consolidated sleep in infancy (Bernier et al., in press). This pattern illustrates that better child sleep promotes child adaptation in the context of positive parenting. Collectively, studies that examined moderation effects illustrate the protective and vulnerability functions of good sleep and poor sleep in various contexts of risk; these studies are consistent with our proposition that sleep may operate as a moderator of risk for adolescents' cognitive functioning in the context of family stress.

\section{The Present Study}

Towards advancing understanding of which youths may be at less or greater risk for poor cognitive functioning in the context of family stress, we examined sleep as a moderator of associations linking marital conflict, harsh parenting, and parental psychological control with youths' cognitive functioning. Our hypotheses are informed by the developmental psychopathology (Cicchetti, 2006) and cumulative risk frameworks (Sameroff et al., 1998), 
which propose that individuals experience risk and protective factors that may interact with their environment to predict adjustment. Consistent with some of the empirical findings (ElSheikh et al., 2010; Lemola et al., 2012), we expected that adolescents exposed to family adversity in conjunction with poor sleep (fewer sleep minutes, reduced sleep efficiency) would exhibit the worst cognitive performance. In contrast, longer and better quality sleep were expected to attenuate the effects of family stress on adolescents' cognitive performance.

We used standardized and well-validated assessments of family stressors and cognitive functioning in a relatively large and diverse sample of adolescents. To decipher unique associations, each family variable was examined while controlling for the other two. Per recommendations of utilizing multiple measures of sleep (Sadeh, 2011), and because sleep duration and quality may have different associations with cognitive functioning (Astill et al., 2012), actigraphy-based sleep minutes and sleep quality indexed through efficiency were assessed. We had no expectations regarding differential effects of the family or sleep parameters.

\section{Method}

\section{Participants}

Data for the current study comes from the fourth wave (data collected in 2012-2013) of the Family Stress Study (FAMSS) a longitudinal project examining relations between family functioning and youth development. Participants were recruited from elementary schools in the Southeastern United States. At the first wave (data collected in 2005), exclusion criteria included a diagnosis of attention deficit hyperactivity disorder, developmental delay or a chronic illness. Eligibility criteria required parents to have been living together for at least two years. Additional families were recruited to participate in the fourth wave to increase sample size due to attrition over a 5-year lag between the third and fourth waves (e.g., families moving away). These additional families were recruited from the same school systems using the same inclusion/exclusion criteria as those in the original sample, and were matched to the original sample's demographics on race/ethnicity and age at the fourth wave.

In the current wave, participants included 199 youths who participated in prior waves (93 boys, 106 girls; $M_{\text {age }}=15.78$ years, $\left.S D=.82\right)$ and an additional 53 adolescents who were recruited to participate in the fourth wave ( 25 boys, 28 girls; $M_{\text {age }}=15.83$ years, $S D=.78$ ). Adolescents who participated for the first time at the fourth wave had lower intellectual ability scores $(M=92.08, S D=10.81)$ than those who participated in prior waves $(M=$ 96.39, $S D=13.78 ; t=-2.02, p<.05)$, but did not differ on any other study variables.

Approximately, 66\% of participants were European American and 34\% were African American. Income-to-needs ratio analyses (U.S. Department of Commerce; www.commerce.gov), which considers income and household/family size, indicated a wide range of economic backgrounds. Families with income-to-needs ratio of $\leq$ were considered to be living in poverty ( $14 \%$ of families). Those with scores $>1$ but $\leq 2$ were considered to be living near the poverty line $(28 \%) ;>2$ but $<3=$ lower middle class $(22 \%) ; \geq 3=$ middle class (36\%). Approximately, $77 \%$ of parents were married and $23 \%$ were unmarried. Of the 
unmarried parents, $83 \%$ were divorced, $12 \%$ were single parents, and $5 \%$ were legal guardians (e.g., grandparent). A majority (58\%) of adolescents lived with both biological parents, 24\% lived with one biological parent and step-parent/partner, $14 \%$ lived in a singleparent household, and $4 \%$ lived with a legal guardian(s).

Procedure

This study is part of a larger, longitudinal investigation and only pertinent procedures are presented. The study was approved by the University's Institutional Review Board. Consent and assent for participation were obtained from parents and adolescents. Sleep data were collected during the regular school year, excluding holidays, via actigraphs that were delivered to participants' homes. Parents and adolescents were instructed to place the actigraph on adolescents' non-dominant wrist before bedtime for seven consecutive nights. Each night, a researcher called to remind adolescents to complete the sleep diary. Nights during which medication was used (reported in sleep diary) were excluded from actigraphy analyses. On average, participants came to the university laboratory 3.95 days $(S D=12.25$ ) after the last night of actigraphy; $79 \%$ of adolescents visited the laboratory the day following the last night of actigraphy. During the laboratory visit, adolescents completed questionnaires and were administered the WJ-III (Woodcock et al., 2001).

\section{Measures}

Marital conflict-Adolescents completed the Conflict Tactics Scale (CTS2; Straus et al., 1996) and reported about mothers' and fathers' physical (e.g., "He/She pushed or shoved him/her"; 12 items) and psychological/verbal (e.g., "Insulted or swore at him/her"; 7 items) aggression towards each other during the past year. Adolescents rated these items on a 7point scale where $0=$ never happened, $1=1$ time, $2=3-5$ times, $4=6-10$ times, $5=11-20$ times, and $6=>20$ times. Physical aggression scores between mothers and fathers were correlated $(r=.48, p<.01)$, as were psychological/verbal aggression scores $(r=.83, p<$. $01)$. Thus, for conciseness, reports of mothers' and fathers' physical (or psychological) aggression were averaged. Approximately $11 \%$ of children reported observing some degree of physical aggression between their parents. Adolescents' reported a wide range of psychological/verbal aggression (scores ranged from 0-25.50). Internal consistency was high for physical aggression $(\alpha=.75)$ and psychological/verbal aggression $(\alpha=.88)$. Additionally, physical and psychological aggression were correlated $(r=.48, p<.01)$; to decrease the number of analyses, these scores were averaged to create a single marital conflict score. Adolescents from single-parent households $(n=31)$ did not have marital conflict scores. Reports of marital conflict (as well as parenting measures detailed below) pertained to biological mothers for $96 \%$ of the sample, father's partner for $4 \%$ of the sample, biological fathers for $80 \%$ of the sample, and mother's partner for $20 \%$ of the sample. Although a few adolescents lived with other caretakers, mother, father, or parent are used throughout for brevity.

Harsh parenting-Adolescents reported on conflict behavior with each parent using the Conflict Tactics Scale (CTS2, Straus et al., 1998). Reports were obtained about mothers' and fathers' use of physical (e.g., "Hit you on the bottom with something like a belt or hard object"; 9 items) and psychological/verbal (e.g., "Said he/she would send you away"; 5 
items) aggression during conflict in the past year. Items were rated on a 7-point scale $(0=$ never happened to $6=>20$ times $)$. Physical $(r=.63, p<.01)$ and psychological/verbal aggression $(r=.54, p<.01)$ scores for mothers and fathers were associated and averaged for each form of aggression. Internal consistency was high for adolescents' report of physical (a $=.85)$ and psychological/verbal $(\alpha=.86)$ aggression. Approximately $49 \%$ of adolescents reported that their parents utilized some degree of physical aggression towards them during conflict. A wide range of psychological/verbal aggression was reported (scores ranged from $0-30)$. Both forms of aggression were associated $(r=.57, p<.01)$ and reports of mothers' and fathers' physical and psychological aggression were averaged to create a single harsh parenting score. For adolescents from single parent households, the harsh parenting composite (as well as parental psychological control detailed below), was based on motherchild conflict in $56 \%$ of cases and father-child conflict in $12 \%$ of cases. For the remaining $32 \%$ of children from single parent households, adolescents reported on both mother-child and father-child conflict, even though they lived primarily with one parent.

Parental psychological control-This construct was assessed through adolescents' report on the Parental Behavior Inventory (PBI; Schaefer, 1965). The PBI has demonstrated reliability and convergent and discriminant validity (Schwarz, Barton-Henry, \& Pruzinksy, 1985). Three scales were used to examine psychological control during the past year: hostile control (e.g., losing temper with child), control through guilt (e.g., feeling hurt when advice is not followed), and instilling persistent anxiety (e.g., talking repeatedly about misbehavior). Adolescents provided separate reports for psychological control for mothers and fathers, and items were rated on a 3 -point scale $(1=$ not like to $3=l i k e)$. Correlations between adolescent reports for mothers and fathers across the three subscales ranged from . 48 to .56 ( $p$ s <.01) and scores for each subscale were averaged across mothers and fathers. Internal consistency was acceptable for hostile control $(\alpha=.73)$, control through guilt $(a=$. $77)$, and instilling persistent anxiety $(\alpha=.81)$. The three subscales were highly associated ( $r$ s ranged from .59 to $.74, p s<.001$ ) and were averaged to create a single score for parental psychological control (scores ranged from 4-12) (e.g., El-Sheikh et al., 2010).

Sleep-Actigraphy is frequently used to derive sleep duration and quality indices and has demonstrated reliability, especially when actigraphs are worn for multiple consecutive nights (Acebo et al., 1999). Sleep measures were obtained using an actigraph by Motionlogger Octagonal Basic (Ambulatory Monitoring Inc., Ardsley, NY). Scores for each epoch were determined with Sadeh's scoring algorithm (Sadeh, Sharkey, \& Carskadon, 1994).

The following sleep parameters were derived: (a) sleep minutes - the number of minutes from sleep onset to wake time; and (b) sleep efficiency - percentage of epochs scored as sleep between sleep onset and offset. Sleep minutes and sleep efficiency scores were generated by averaging data across all available nights.

On average, 5.44 nights $(S D=1.77)$ of actigraphy data were available per adolescent. Many youths had available data for the entire week $(33 \%, n=83) ; 26 \%(n=65)$ had data for six nights, $18 \%(n=45)$ for five nights, $9 \%(n=23)$ for four nights, $4 \%(n=12)$ for three nights, $2 \%(n=4)$ for two nights, $1 \%(n=1)$ for one night. Approximately $7 \%(n=18)$ of 
participants did not have any actigraphy data. Because of poor estimation of regular sleep (Meltzer, Montgomery-Downs, Insana \& Walsh, 2012), sleep data for adolescents with fewer than five nights of available actigraphy data $(n=58,23 \%)$ were not included. Reasons for missing data included taking medicine for allergies, forgetting to wear the actigraph, and mechanical problems. Night-to-night stability during the week was acceptable for sleep efficiency $(\alpha=.95)$ and sleep minutes $(\alpha=.75)$.

Intellectual ability-Intellectual ability was assessed with the Woodcock-Johnson III (WJ-III), which is a well-normed, highly reliable and valid comprehensive measure for assessing general and specific domains of intellectual ability. Age norm based scaled scores have a mean of $100(S D=15)$. For the present study, we used the Brief Intellectual Ability (BIA) index which is comprised of three tests: Verbal Comprehension (VC), Concept Formation (CF), and Visual Matching (VM). The VC test includes picture vocabulary, verbal analogies, synonyms, and antonyms and is considered a strong indicator of crystallized intelligence. The $\mathrm{CF}$ test measures fluid and inductive reasoning, as well as flexibility in shifting mental set, a dimension of executive functioning. Lastly, the VM test assesses perceptual processing speed. In the standardization sample, BIA had a median reliability of 0.95 across ages and was highly correlated $(r=.91)$ with the Generalized Intellectual Ability index, which is based on 10 tests (Woodcock et al., 2001).

Controls-Some variables were associated with the primary model variables and were controlled in analyses including child sex $(0=$ girls, $1=$ boys $)$; race/ethnicity $(0=$ European American, 1 = African American); and family income-to-needs ratio. Further, three additional variables were included as controls in all analyses: parental marital status $(0=$ married, $1=$ unmarried $)$, biological mother status $(0=$ biological mother, $1=$ father's partner), and biological father status $(0=$ biological father, $1=$ mother's partner $)$.

\section{Plan of Analysis}

To reduce outlier effects, study variable values that exceeded $4 S D$ s were recoded as the highest (or lowest) observed value within $4 S D$ s. In total, eight values were recoded, including one for marital psychological aggression, four for marital physical aggression, two for parent-child physical aggression, and one for sleep efficiency. Skewness statistics and missing data (8\% to $23 \%)$ across all study variables were within the acceptable range.

Descriptive statistics and correlations among variables were examined in preliminary analyses. Next, a series of cross-sectional path models were fitted in Amos (Arbuckle, 2012) to examine whether family stressors, sleep, and importantly the interactions between family stressors and sleep predicted adolescent intellectual ability. Full information maximum likelihood (FIML) estimation was used to handle missing data (Acock, 2005). Separate models were fitted for each sleep parameter and all control and predictor variables were mean-centered for analyses. Significantly correlated exogenous variables were allowed to covary.

In all models, gender, ethnicity, income-to-needs ratio, parental marital status, and biological parent status were included as covariates and allowed to predict intellectual ability. Next, the main effects of family stressors (marital conflict, harsh parenting, and 
psychological control) were entered simultaneously to examine the independent contributions of each on intellectual ability, while controlling for the effects of the other family variables. This was followed by the entry of the main effect of sleep minutes or sleep efficiency. Lastly, interaction terms were added to examine whether sleep moderated the relations between family stress and intellectual ability. Only one interaction term (e.g., marital conflict $\times$ sleep minutes) was examined at a time in consideration of power and multicollinearity (Babyak, 2004).

The Preacher, Curran, and Bauer's (2006) interaction utility was used to plot significant interactions at low $(-1 S D)$ and high (+1 $S D)$ levels of the predictor (family variable) and moderator (sleep) (Aiken \& West, 1991). Simple slopes were tested to determine whether the predictor was significantly associated with the outcome at a specific level of the moderator.

\section{Results}

\section{Preliminary Analyses}

Descriptive statistics and correlations are presented in Table 1. Marital conflict was correlated with harsh parenting, and the latter was associated with parental psychological control. Sleep minutes and sleep efficiency were correlated. Family stressors were not associated with sleep or intellectual ability, and the latter two were not correlated.

Among control variables (not depicted in a Table 1), higher socioeconomic background was associated with lower levels of harsh parenting $(r=-.15, p<.05)$, longer sleep minutes $(r=$. $16, p<.05)$, greater sleep efficiency $(r=.16, p<.05)$, and higher intellectual ability scores $(r=.21, p<.01)$. Additionally, living in a household with unmarried partners was correlated with lower socioeconomic status $(r=-.33, p<.001)$ and shorter sleep minutes $(r$ $=-.15, p<.05)$.

Tests of mean differences for adolescent sex and race/ethnicity were conducted. Boys had fewer sleep minutes $(M=391.88, S D=53.24)$ than girls $(M=418.78, S D=53.36 ; t=3.49$, $p<.01)$, as well as lower sleep efficiency $\left(M_{\text {boys }}=89.50, S D=6.90 ; M_{\text {girls }}=92.07, \mathrm{SD}=\right.$ $6.40 ; t=2.70, p<.01$ ). Compared to European American (EA) children, African American (AA) children were from households with lower income-to-needs ratio $\left(M_{\mathrm{AA}}=1.89, S D=\right.$ $\left.1.21 ; M_{\mathrm{EA}}=2.64, S D=1.28 ; t=4.39, p<.001\right)$, reported higher levels of harsh parenting $\left(M_{\mathrm{AA}}=4.71, S D=4.07 ; M_{\mathrm{EA}}=3.23, S D=3.61 ; t=-2.81, p<.01\right)$, had fewer sleep minutes $\left(M_{\mathrm{AA}}=387.97, S D=61.93 ; M_{\mathrm{EA}}=413.52, S D=50.27 ; t=2.96, p<.01\right)$, and lower intellectual ability scores $\left(M_{\mathrm{AA}}=92.71, S D=12.71 ; M_{\mathrm{EA}}=96.91, S D=13.40 ; t=\right.$ $2.28, p<.05)$.

\section{Family Stress × Sleep Efficiency}

Results from the series of path models are presented in Table 2. For parsimony, all moderation effects are shown in the same step yet the coefficients presented are the result of entering one interaction term at a time. Among the control variables, income-to-needs ratio, but not gender, ethnicity, parental marital status, or parent status, positively predicted intellectual ability. Main effects of marital conflict, harsh parenting, and parental 
psychological control did not emerge. Further, sleep efficiency did not predict intellectual ability.

The model examining marital conflict by sleep efficiency yielded a good fit to the data, $\chi^{2}=$ $46.35, p=.30 ; \chi^{2} / \mathrm{df}=1.10 ; \mathrm{CFI}=.98 ;$ RMSEA $=.02 n s, 90 \%$ CI [.00 to .05$]$, and explained $10.7 \%$ of the variance in adolescent cognitive performance. However, as shown in Table 2, an interaction between marital conflict and sleep efficiency did not reach statistical significance.

The model examining harsh parenting by sleep efficiency was also a good fit to the data, $\chi^{2}$ $=43.81, p=.43 ; \chi^{2} / \mathrm{df}=1.02 ; \mathrm{CFI}=1.00 ; \mathrm{RMSEA}=.01 \mathrm{~ns}, 90 \% \mathrm{CI}$ [.00 to .04$]$, and explained $11.4 \%$ of the variance in adolescent intellectual ability. An interaction emerged between harsh parenting and sleep efficiency, which explained $2 \%$ of unique variance in intellectual ability (Table 2). Graphic depiction of the interaction is shown in Figure 1. Tests of simple slopes did not reveal a significant association between harsh parenting and intellectual ability at lower $(B=.45, S E=.40, p=.26)$ or higher $(B=-.50, S E=.40, p=.21)$ levels of sleep efficiency. Visual inspection of the data indicates that at lower levels of harsh parenting, adolescents with higher sleep efficiency had higher levels of intellectual ability (estimated level $=98.31$ ) than those with lower sleep efficiency (estimated level $=93.53$ ), a difference of approximately $.36 S D$ s. Regions of significance test indicated that the association between harsh parenting and intellectual ability becomes significant at $2.68 S D \mathrm{~s}$ above the mean on sleep efficiency. Taken together, it appears that higher levels of intellectual ability are observed when adolescents receive higher-quality sleep and experience low levels of harsh parenting.

Lastly, the model examining parental psychological control by sleep efficiency was a good fit to the data, $\chi^{2}=43.93, p=.43 ; \chi^{2} / \mathrm{df}=1.02 ; \mathrm{CFI}=1.00 ; \mathrm{RMSEA}=.01 n s, 90 \%$ CI $[.00$ to .04], and explained $12.2 \%$ of the variance in intellectual ability. An interaction between parental psychological control and sleep efficiency emerged, explaining $2.8 \%$ of unique variance in intellectual ability (Table 2). Simple slopes analyses revealed that a negative significant slope characterized the relation between psychological control and intellectual ability $(B=-1.73, S E=.76, p<.05)$ when sleep efficiency was high. For these youths, estimated levels of intellectual ability were higher at lower (99.44) versus higher (93.59) levels of psychological control. When sleep efficiency was low, the slope was not significant and intellectual ability did not differ based on psychological control $(B=.45, S E=.76, p=$. 55). Additionally, at low levels of psychological control, intellectual ability test scores were higher at higher levels of sleep efficiency (estimated level $=99.44$ ) compared to lower levels of sleep efficiency (estimated level =94.39), a difference of about .38 SDs. At high levels of psychological control, intellectual ability scores appear similar regardless of sleep. Regions of significance test indicated that the association between psychological control and intellectual ability was significant at $43 S D$ s above the mean on sleep efficiency. Similar to the pattern of effects observed for harsh parenting, Figure 2 illustrates that the highest levels of cognitive performance were evident for youths with both higher sleep efficiency in conjunction with lower psychological control. 
Models examining the effect of sleep minutes did not yield significant main effects or interactions involving the family stress variables. Thus, these results are not reported.

\section{Discussion}

Intellectual ability is a uniquely consequential asset with long-term implications for educational attainment, occupational success, and psychological adjustment. Despite its relatively high stability, research suggests that intellectual ability may be influenced by family experiences (Byford et al., 2012; Koenen et al., 2003; Ybarra et al., 2007). At the same time, studies suggest that bioregulatory factors may exacerbate or attenuate the risk associated with family stress (El-Sheikh \& Erath, 2011). The present study is the first to examine sleep as a moderator of associations between multiple dimensions of family stress and intellectual ability in a relatively large and diverse sample of adolescents. Marital conflict, harsh parenting, and parental psychological control were assessed with wellvalidated adolescent reports; sleep duration and sleep quality were assessed objectively via actigraphy; and intellectual ability was indexed through cognitive performance on standardized tests. Several potential confounds were controlled, including variables representing socioeconomic status and family structure.

No direct associations between family stress and cognitive functioning emerged. However, harsh parenting and parental psychological control interacted with sleep quality to predict cognitive performance, suggesting that sleep quality may alter the association between negative parenting and intellectual ability. Notably, psychological control and harsh parenting were only modestly correlated, yet interacted with sleep quality in a similar manner to predict cognitive performance. Thus, although harsh parenting and psychological control may be linked with intellectual ability via a similar interactive process, these forms of negative parenting do not necessarily co-occur within families, underscoring the value of considering multiple dimensions of family stress to advance a more complete understanding of the predictors of intellectual ability. Although it approached statistical significance, marital conflict did not interact significantly with sleep quality to predict cognitive functioning, but was strongly correlated with harsh parenting. Interactive associations linking harsh parenting, but not marital conflict, with intellectual ability may be related to the extent to which adolescents are targeted directly in the case of harsh parenting compared to marital conflict, though further research will be necessary before any conclusions can be drawn.

The most notable result of the present study involved the interaction between parental psychological control and sleep quality. Higher psychological control was significantly associated with lower intellectual ability among adolescents with better sleep quality, but not among adolescents with poorer sleep quality. These results indicate that adolescents who sleep well and experience low levels of psychological control demonstrate the highest intellectual ability. However, the benefits of high quality sleep may be less pronounced when adolescents experience higher levels of psychological control. These findings are consistent with the protective-reactive moderating process proposed by Luthar, Cicchetti, and Becker (2000), as high quality sleep was generally advantageous in the context of lowrisk parenting (i.e., low psychological control, low harsh parenting), but less advantageous 
in the context of high-risk parenting. Building on existing literature, this finding suggests that good quality sleep may not only be protective against negative contexts (Buckhalt et al., 2009; El-Sheikh et al., 2010), but also beneficial in more positive contexts (Bernier et al., in press; Bordeleau et al., 2012).

Neither psychological control nor harsh parenting was associated with intellectual ability among adolescents with relatively low quality sleep. This pattern of moderation effects is not consistent with expectations informed by the cumulative risk framework (Sameroff et al., 1998). Rather, it appears that adolescents with poor sleep quality did not benefit from low-risk parenting compared to those with better sleep. Although patterns of moderation effects are difficult to replicate, clarification of the nature of vulnerability and protection associated with children's sleep in the context of family functioning is an important avenue for future research.

The stronger association between negative parenting and poorer adjustment among adolescents with better sleep (rather than poorer sleep) shows both consistencies and inconsistencies with published work that varies based on development period, sleep measures, and/or outcome variables. In comparison to adolescents with better sleep, interparental conflict was more strongly associated with aggression among youths who reported shorter weekday sleep duration and greater differences in sleep duration between weekdays and weekends (Lemola et al., 2012). Further, better sleep quality, assessed via actigraphy, protected children against internalizing problems otherwise associated with parental psychological control in late childhood, although the protective effect of better sleep was limited to children from higher SES families (El-Sheikh et al., 2010). Thus, moderation findings of Lemola et al. and El-Sheikh et al. are different from those observed in the present study. More consistent with findings of the current investigation, stronger associations linking maternal sensitivity with children's lower internalizing and externalizing symptoms (Bordeleau et al., 2012) and greater attachment security (Bernier et al., in press) were observed among young children with longer versus shorter sleep duration. Similarly, in comparison to children with less consolidated sleep in infancy, a stronger association linking maternal sensitivity with executive functioning and perspective taking emerged for those with more consolidated sleep (Bernier et al., in press). In these studies and the present study, the highest levels of positive outcomes were observed for children with more positive parenting and better sleep. Overall, the pertinent literature is underdeveloped and mixed, and it remains unclear whether family relationship experiences and child adaptation are more strongly related among children with better sleep (as suggested by the current study, Bernier et al., in press, and Bordeleau et al., 2012) or poorer sleep (El-Sheikh et al., 2010; Lemola et al., 2012).

Sleep efficiency, but not sleep minutes, moderated relations between family stress and intellectual ability. Several studies have reported associations between sleep quality, but not duration, and either adjustment outcomes or family stress (Sadeh et al., 2000). In the context of sleep deprivation, a compensatory mechanism may extend the sleep period yet this may not translate into better quality sleep (Sadeh et al., 2003). Poor sleep efficiency can disrupt prefrontal cortex processes, which are integral to executive functioning (Dahl, 1996; Muzur, 
Pace-Schott, \& Hobson, 2002), such as disruptions in emotional memory (Walker \& van der Helm, 2009).

Although interactions between family stress and sleep emerged, direct associations linking either family stress or adolescent sleep with intellectual ability were not observed. In the literature, both null and modest effects linking either family stress (Byford et al., 2012; Koenen et al., 2003; Ybarra et al., 2007) or sleep (Astill et al., 2012) and cognitive functioning and intellectual ability have been found. Additionally, the association between sleep and intellectual ability has been moderated by other factors, such as SES (Buckhalt et al., 2009). Further, the link between family stress and intellectual ability may be moderated by other factors, as found in the present study. Further identification of individual differences and contexts that may affect the association between family functioning and children's development across multiple domains is imperative for identifying for whom and under which conditions these relations are evident.

It is important to note several limitations of the present study and directions for future research. The cross-sectional design does not permit conclusions about directionality or causality; given the stability of intellectual ability, and thus the potentially high threshold for environmental stress to influence intellectual ability, longitudinal data beginning in childhood are needed to replicate and extend our results. It is also worth noting that the magnitude of effects in the present study was generally modest, underscoring the need for further tests of the hypotheses under investigation and highlighting the potential importance of multiple untested variables that could underlie intellectual ability. Although we referred to the potentially different protective functions of sleep in different contexts, it will be useful for future research to directly compare sleep as a moderator of multiple forms of environmental risk, such as family, peer, and socioeconomic stress. In addition, whereas the objective assessment of sleep quality is a strength of the present study, hypotheses were not supported with the measure of sleep duration. Thus, measuring multiple dimensions of sleep-wake processes may help clarify the unique roles of different dimensions of sleep. Despite the need to advance the current study before strong conclusions can be drawn, this multi-method study provides the first evidence that sleep moderates associations linking parental psychological control and harsh parenting with intellectual ability during adolescence, and therefore contributes to a multi-dimensional conceptualization of some of the predictors of intellectual ability.

\section{Acknowledgements}

This research was supported by Grant R01-HD046795 from the Eunice Kennedy Shriver National Institute of Child Health and Human Development awarded to Mona El-Sheikh. The content is solely the responsibility of the authors and does not necessarily represent the official views of the National Institutes of Health. We wish to thank the staff of our research laboratory, most notably Bridget Wingo, for data collection and preparation, and the school personnel, children, and parents who participated.

\section{References}

Acebo C, Sadeh A, Seifer R, Tzischinsky O, Wolfson A, Hafer A, Carskadon MA. Estimating sleep patterns with actigraphy monitoring in children and adolescents: How many nights are necessary for reliable measures? Sleep. 1999; 22:95-103. [PubMed: 9989370] 
Acock AC. Working with missing values. Journal of Marriage and Family. 2005; 67:1012-1028. doi: 10.1111/j.1741-3737.2005.00191.x.

Aiken, LS.; West, SG. Multiple regression: Testing and interpreting interactions. Sage; Newbury Park, CA: 1991.

Arbuckle J. Amos 21 user's guide: Amos Development Corporation. 2012

Astill RG, Van der Heijden KB, Van Ijzendoorn MH, Van Someren EJ. Sleep, cognition, and behavioral problems in school-age children: A century of research meta-analyzed. Psychological Bulletin. 2012; 138:1109-1138. doi: 10.1037/a0028204. [PubMed: 22545685]

Babyak MA. What you see may not be what you get: A brief, nontechnical introduction to overfitting in Regression-type models. Psychosomatic Medicine. 2004; 66:411-421. doi: 10.1097/01.psy. 0000127692.23278.a9. [PubMed: 15184705]

Barber, BK. Parental psychological control of children and adolescents. American Psychological Association; Washington, DC: 2002.

Baum KT, Desai A, Field J, Miller LE, Rausch J, Beebe DW. Sleep restriction worsens mood and emotion regulation in adolescents. Journal of Child Psychology and Psychiatry. 2014; 55:180-190. [PubMed: 24889207]

Bean RA, Bush KR, McKenry PC, Wilson SM. The impact of parental support, behavioral control, and psychological control on the academic achievement and self-esteem of African American and European American adolescents. Journal of Adolescent Research. 2003; 18:523-541. doi: 10.1177/0743558403255070.

Beebe DW. Cognitive, behavioral, and functional consequences of inadequate sleep in children and adolescents. Pediatric Clinics of North America. 2011; 58:649-665. doi: 10.1016/j.pcl. 2011.03.002. [PubMed: 21600347]

Bernier A, Bélanger M-È, Tarabulsy GM, Simard V, Carrier J. Child sleep as a moderator of relations between maternal sensitivity and child outcomes. Infant Behavior and Development. (in press).

Bordeleau S, Bernier A, Carrier J. Maternal sensitivity and children's behavior problems: Examining the moderating role of infant sleep duration. Journal of Clinical Child \& Adolescent Psychology. 2012; 41:471-481. [PubMed: 22642676]

Buckhalt JA, El-Sheikh M, Keller PS, Kelly RJ. Concurrent and longitudinal relations between children's sleep and cognitive functioning: the moderating role of parent education. Child Development. 2009; 80:875-892. doi: 10.1111/j.1467-8624.2009.01303.x. [PubMed: 19489909]

Buehler C, Gerard JM. Cumulative family risk predicts increases in adjustment difficulties across early adolescence. Journal of Youth and Adolescence. 2013; 42:905-920. doi: 10.1007/ s10964-012-9806-3. [PubMed: 22915131]

Byford M, Kuh D, Richards M. Parenting practices and intergenerational associations in cognitive ability. International Journal of Epidemiology. 2012; 41:263-272. doi: 10.1093/ije/dyr188. [PubMed: 22422461]

Cicchetti, D. Development and psychopathology.. In: Cicchetti, D.; Cohen, DJ., editors. Developmental psychopathology. 2nd ed.. Vol. 1. Wiley; New York: 2006. p. 1-23.

Crowley, SJ.; Tarokh, L.; Carskadon, MA. Sleep during adolescence.. In: Sheldon, SH.; Ferber, R.; Kryger, MH.; Gozal, D., editors. Principles and practice of pediatric sleep medicine. Elsevier, Inc.; Atlanta, GA: 2014. p. 45-52.

Cummings, EM.; Davies, PT. Marital conflict and children: An emotional security perspective. 1 ed.. The Guilford Press; New York: NY: 2011.

Dahl RE. The impact of inadequate sleep on children's daytime cognitive function. Seminars in Pediatric Neurology. 1996; 3:44-50. doi: 10.1016/S1071-9091(96)80028-3. [PubMed: 8795841]

Dahl, R.; Spear, L. Adolescent brain development: Vulnerabilities and opportunities. Vol. 1021. New York Academy of Sciences; New York: 2004.

Dewald-Kaufmann JF, Oort FJ, Meijer AM. The effects of sleep extension on sleep and cognitive performance in adolescents with chronic sleep reduction: An experimental study. Sleep Medicine. 2013; 14:510-517. doi: 10.1016/j.sleep.2013.01.012. [PubMed: 23523432]

Dotterer AM, Hoffman L, Crouter AC, McHale SM. A longitudinal examination of the bidirectional links between academic achievement and parent-adolescent conflict. Journal of Family Issues. 2008; 29:762-779. doi: 10.1177/0192513X07309454. 
El-Sheikh, M. Sleep and development: Familial and socio-cultural considerations. Oxford University Press; New York: 2011.

El-Sheikh M, Erath SA. Family conflict, autonomic nervous system functioning, and child adaptation: State of the science and future directions. Development and Psychopathology. 2011; 23:703-721. doi: 10.1017/S0954579411000034. [PubMed: 23786705]

El-Sheikh M, Hinnant JB, Kelly RJ, Erath S. Maternal psychological control and child internalizing symptoms: Vulnerability and protective factors across bioregulatory and ecological domains. Journal of Child Psychology and Psychiatry. 2010; 51:188-198. doi: 10.1111/j. 1469-7610.2009.02140.x. [PubMed: 19703095]

Erel O, Burman B. Interrelatedness of marital relations and parent-child relations: a meta-analytic review. Psychological Bulletin. 1995; 118:108-132. [PubMed: 7644602]

Estrada P, Arsenio WF, Hess RD, Holloway SD. Affective quality of the mother-child relationship: Longitudinal consequences for children's school-relevant cognitive functioning. Developmental Psychology. 1987; 23:210-215. doi: 10.1037/0012-1649.23.2.210.

Gruber R, Cassoff J, Frenette S, Wiebe S, Carrier J. Impact of sleep extension and restriction on children's emotional lability and impulsivity. Pediatrics. 2012; 130:e1155-e1161. doi: 10.1542/ peds.2012-0564. [PubMed: 23071214]

Hinnant JB, El-Sheikh M, Keiley M, Buckhalt JA. Marital Conflict, Allostatic Load, and the Development of Children's Fluid Cognitive Performance. Child Development. 2013; 84:2003 2014. doi: 10.1111/cdev.12103. [PubMed: 23534537]

Jan JE, Reiter RJ, Bax MCO, Ribary U, Freeman RD, Wasdell MB. Long-term sleep disturbances in children: A cause of neuronal loss. European Journal of Paediatric Neurology. 2010; 14:380-390. doi: 10.1016/j.ejpn.2010.05.001. [PubMed: 20554229]

Kaufman SB, Reynolds MR, Liu X, Kaufman AS, McGrew KS. Are cognitive and academic achievement one and the same? An exploration on the Woodcock-Johnson and Kaufman tests. Intelligence. 2012; 40:123-138. doi: 10.1016/j.intell.2012.01.009.

Keller PS, El-Sheikh M, Buckhalt JA. Children's attachment to parents and their academic functioning: Sleep disruptions as moderators of effects. Journal of Developmental \& Behavioral Pediatrics. 2008; 29:441-449. doi: 10.1097/DBP.0b013e318182a9b4. [PubMed: 18714206]

Klahr AM, McGue M, Iacono WG, Burt SA. The association between parent- child conflict and adolescent conduct problems over time: Results from a longitudinal adoption study. Journal of Abnormal Psychology. 2011; 120:46-56. doi: 10.1037/a0021350. [PubMed: 21038930]

Koenen KC, Moffitt TE, Caspi A, Taylor A, Purcell S. Domestic violence is associated with environmental suppression of IQ in young children. Development and Psychopathology. 2003; 15:297-311. doi: 10.1017/S0954579403000166. [PubMed: 12931829]

Lemola S, Schwarz B, Siffert A. Interparental conflict and early adolescents' aggression: Is irregular sleep a vulnerability factor? Journal of Adolescence. 2012; 35:97-105. doi: 10.1016/j.adolescence. 2011.06.001. [PubMed: 21733568]

Leotta C, Carskadon MA, Acebo C, Seifer R, Quinn B. Effects of acute sleep restriction on affective response in adolescents: Preliminary results. Sleep Research. 1997; 26:201.

Longmore, MA.; Manning, WD.; Giordano, PC. Parent-child relationships in adolescence.. In: Fine, MA.; Fincham, FD., editors. Handbook of family theories: A content-based approach. Taylor \& Francis; New York, NY: 2013. p. 28-50.

Luthar SS, Cicchetti D, Becker B. The construct of resilience: A critical evaluation and guidelines for future work. Child Development. 2000; 71:543-562. doi: 10.1111/1467-8624.00164. [PubMed: 10953923]

McEwen BS. The brain is the central organ of stress and adaptation. NeuroImage. 2009; 47:911-913. doi: 10.1016/j.neuroimage.2009.05.071. [PubMed: 19501171]

Meltzer LJ, Montgomery-Downs HE, Insana SP, Walsh CM. Use of actigraphy for assessment in pediatric sleep research. Sleep Medicine Reviews. 2012; 16:463-475. doi: 10.1016/j.smrv. 2011.10.002. [PubMed: 22424706]

Mindell, J.; Owens, J. A clinical guide to pediatric sleep. diagnosis and management of sleep problems. Lippincott Williams \& Wilkins; New York, NY: 2010. Evaluation of pediatric sleep disorders.; p. 30-42. 
Muzur A, Pace-Schott EF, Hobson JA. The prefrontal cortex in sleep. Trends in Cognitive Sciences. 2002; 6:475-481. doi: 10.1016/s1364-6613(02)01992-7. [PubMed: 12457899]

Preacher KJ, Curran PJ, Bauer DJ. Computational tools for probing interactions in multiple linear regression, multilevel modeling, and latent curve analysis. Journal of Educational and Behavioral Statistics. 2006; 31:437-448. doi: 10.3102/10769986031004437.

Romeo RD. The teenage brain the stress response and the adolescent brain. Current Directions in Psychological Science. 2013; 22:140-145. doi: 10.1177/0963721413475445.

Sadeh, A. Sleep assessment methods.. In: El-Shiekh, M., editor. Sleep and development: Familial and socio-cultural considerations. Oxford University Press; New York, NY: 2011. p. 355-371.

Sadeh A, Gruber R, Raviv A. The effects of sleep restriction and extension on school-aged children: What a difference an hour makes. Child Development. 2003; 74:444-455. [PubMed: 12705565]

Sadeh A, Raviv A, Gruber R. Sleep patterns and sleep disruptions in school-age children. Developmental Psychology. 2000; 36:291-301. doi: 10.1111/1467-8624.7402008. [PubMed: 10830974]

Sadeh A, Sharkey KM, Carskadon MA. Activity-based sleep-wake identification: an empirical test of methodological issues. Sleep. 1994; 17:201-207. [PubMed: 7939118]

Sameroff, AJ.; Bartko, WT.; Baldwin, A.; Baldwin, C.; Seifer, R. Family and social influences on the development of child competence.. In: Lewis, M.; Feiring, C., editors. Families, risk, and competence. New York Lawrence Erlbaum Associates; 1998. p. 161-185.

Schaefer ES. Children's reports of parental behavior: An inventory. Child Development. 1965; 36:413434. doi: 10.2307/1126465. [PubMed: 14300862]

Schwarz JC, Barton-Henry ML, Pruzinsky T. Assessing child-rearing behaviors: A comparison of rating made by mother, father, child, and sibling on the CRPBI. Child Development. 1985; 56:462-479. doi: 10.2307/1129734. [PubMed: 3987419]

Shumow L, Vandell DL, Posner JK. Harsh, firm, and permissive parenting in low-income families relations to children's academic achievement and behavioral adjustment. Journal of Family Issues. 1998; 19:483-507. doi: 10.1177/019251398019005001.

Soenens B, Luyckx K, Vansteenkiste M, Luyten P, Duriez, Goossens L. Maladaptive perfectionism as an intervening variable between psychological control and adolescent depressive symptoms: A three-wave longitudinal study. Journal of Family Psychology. 2008; 22:465-474. doi: 10.1037/0893-3200.22.3.465. [PubMed: 18540775]

Straus MA, Hamby SL, Boney-McCoy S, Sugarman DB. The revised Conflict Tactics Scales (CTS-2): Development and preliminary psychometric data. Journal of Family Issues. 1996; 17:283-316. doi: 10.1177/019251396017003001.

Straus MA, Hamby SL, Finkelhor D, Moore DW, Runyan D. Identification of child maltreatment with the parent-child Conflict Tactics Scales: Development and psychometric data for a national sample of American parents. Child Abuse and Neglect. 1998; 22:249-270. [PubMed: 9589178]

Vriend JL, Davidson FD, Corkum PV, Rusak B, Chambers CT, McLaughlin EN. Manipulating sleep duration alters emotional functioning and cognitive performance in children. Journal of Pediatric Psychology. 2013; 38:1058-1069. doi: 10.1093/jpepsy/jst033. [PubMed: 23720415]

Walker MP, van der Helm E. Overnight therapy? The role of sleep in emotional brain processing. Psychological Bulletin. 2009; 135:731-748. doi: 10.1037/a0016570. [PubMed: 19702380]

Woodcock, RW.; McGrew, KS.; Mather, M. Woodcock-Johnson III Tests of Cognitive Abilities. Riverside Publishing; NY: 2001.

Ybarra GJ, Wilkens SL, Lieberman AF. The influence of domestic violence on preschooler behavior and functioning. Journal of Family Violence. 2007; 22:33-42. doi: 10.1007/s10896-006-9054-y. 


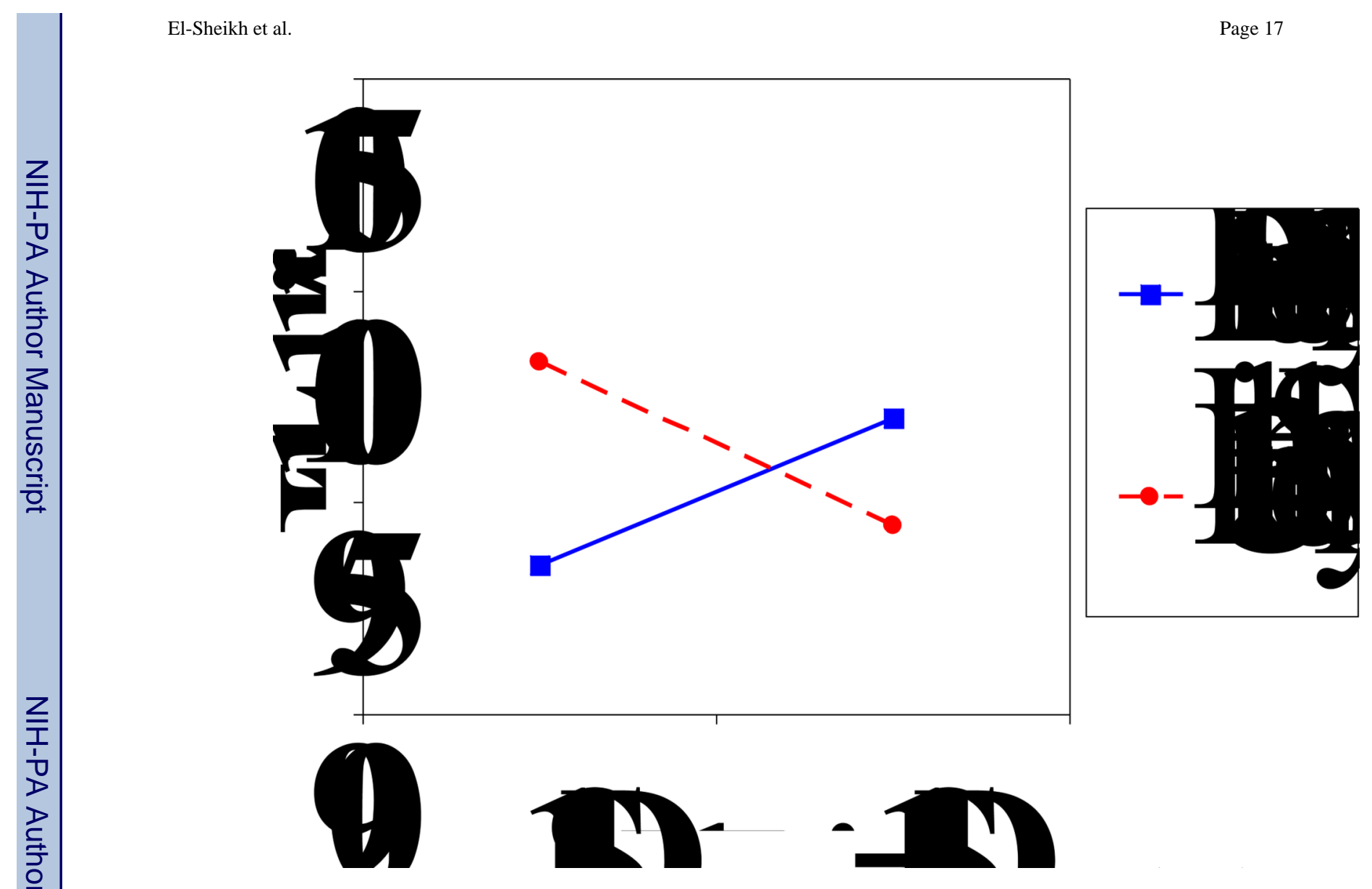

Figure 1.

Sleep efficiency as a moderator of the relations between harsh parenting and adolescents' intellectual ability. 


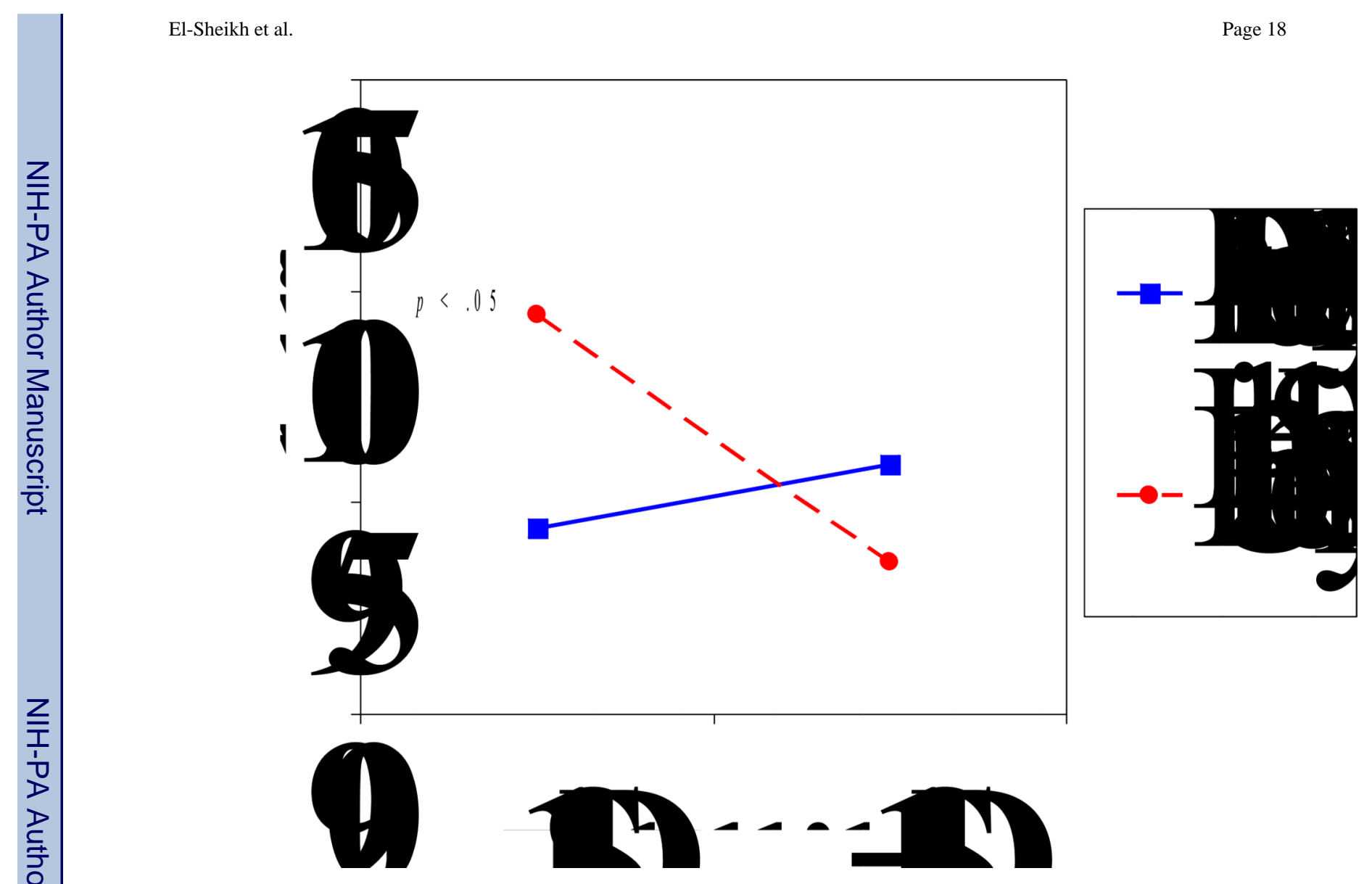

Figure 2.

Sleep efficiency as a moderator of the relations between parental psychological control and adolescents' intellectual ability. 


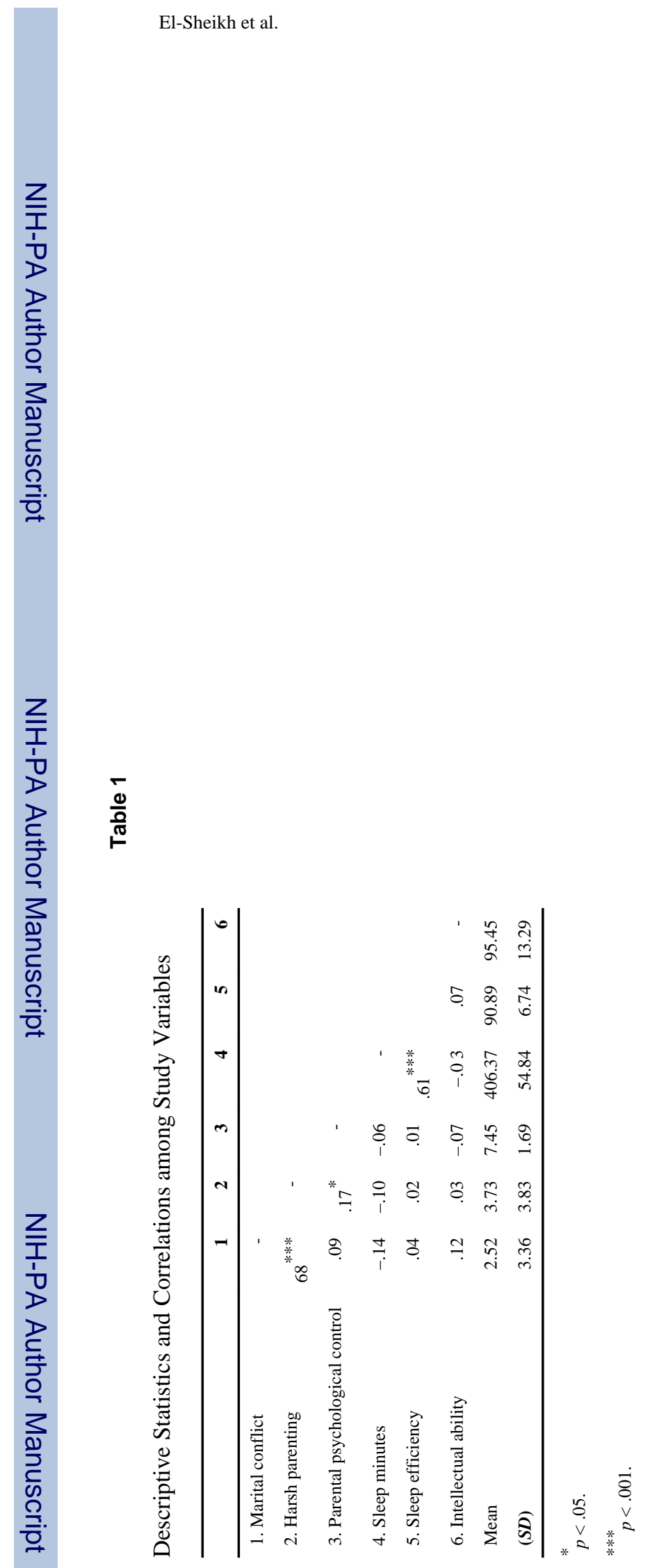

J Fam Psychol. Author manuscript; available in PMC 2015 December 01. 


\section{Table 2}

\section{Unstandardized and Standardized Coefficients of Associations Linking Family Stress and Adolescent Sleep} with Intellectual Ability

\begin{tabular}{lcccc}
\hline & \multicolumn{4}{c}{ Intellectual ability } \\
\cline { 2 - 5 } & $\boldsymbol{B}$ & $\boldsymbol{S} \boldsymbol{E}$ & $\boldsymbol{\beta}$ & $\mathbf{R}^{2}$ \\
\hline Step 1 & & & & $6.6 \%$ \\
$\quad$ Sex & .75 & 1.74 & .03 & \\
Ethnicity & -2.86 & 1.87 & -.10 & \\
Income-to-needs & 1.82 & .74 & $.1{ }^{*}$ & \\
Marital status & -1.35 & 2.24 & -.04 & \\
Biological mother & -6.89 & 4.81 & -.10 & \\
Biological father & 2.03 & 2.43 & .06 & \\
Step 2 & & & & $9.4 \%$ \\
Marital conflict (MC) & .52 & .37 & .14 & \\
Harsh parenting (HP) & -.04 & .34 & -.01 & \\
Psychological control (PC) & -.62 & .52 & -.08 & \\
Step 3 & & & & $9.4 \%$ \\
Sleep efficiency & .08 & .15 & .04 & \\
Step 4 & & & & \\
MC $\times$ Sleep efficiency & -.07 & .04 & -.13 & $10.7 \%$ \\
HP $\times$ Sleep efficiency & -.07 & .04 & -.14 & $11.4 \%$ \\
PC $\times$ Sleep efficiency & -.16 & .08 & -.14 & $12.2 \%$ \\
\hline
\end{tabular}

Note. Sex coded $0=$ girls, $1=$ boys; ethnicity coded $0=$ European American, $1=$ African American; marital status coded $0=$ married, $1=$ unmarried; biological mother coded $0=$ biological mother, $1=$ father's partner; biological father coded $0=$ biological father, $1=$ mother's partner. Interactions were examined one at a time, controlling for the main effects of other family stress variables. Significantly correlated exogenous variables were allowed to covary.

* $p<.05$. 